\title{
Vague eggs and tags: Prevelar merger in Seattle
}

\author{
VALERIE FreEMAN \\ Oklahoma State University
}

\section{A B S T R AC T}

This study describes prevelar merger, the raising of low-front $/ \mathfrak{x}, \varepsilon /$ and lowering of mid-front $/ \mathrm{e} /$ before the voiced velar $/ \mathrm{g} /$, in Seattle, Washington. In the most advanced part of this change in progress, all twenty speakers (age 18-62, half men, half women, all white) produced $/ \mathrm{\varepsilon g} /$ and /eg/ (BEG, VAGUE) as upgliding diphthongs merged in F1 and F2 directly between their nonprevelar counterparts (DRESS, FACE). / æg/ (BAG) was also diphthongal, but its height varied between speakers, with middle-aged men showing near-complete three-way merger with BEG-VAGUE and younger speakers raising less, suggesting reversal or avoidance of this component. Previous work lacked information about VAGUE and thus described BAG- and BEG-raising as failing to reach the height of nonprevelar FACE. This study revealed that VAGUE is lowered, creating a merger target for both raised BEG and BAG within a separate diphthongal prevelar subsystem.

The focus of this study is prevelar merger in two generations of white Seattleites. Prevelar merger is a combination of prevelar raising, the raising of the low front vowels /æ, $\varepsilon$ / (TRAP, DRESS classes) before voiced velars (also called BAG-raising and BEG-raising), and the previously understudied lowering of mid front /e/ (FACE class) before the voiced velar /g/ (vAGUE-lowering). Recent years have seen an increase in sociolinguistic research on both prevelar raising and Pacific Northwest English (PNWE). Various forms of prevelar raising have been found in regions across the Northern US and Canada, with the particular combination of high degrees of both BAG- and BEG-raising serving as a possible means of differentiating a Pacific Northwest dialect from its neighbors. However, this study proposes that the pattern is incomplete without considering a third prevelar class: VAGUE.

Raised BEG, and often also raised BAG, have been described as sounding like FACE, but acoustic studies consistently measure their heights as nearing, but not reaching, nonprevelar FACE, making it difficult to declare that prevelars are merged with FACE. The current study addresses this issue by proposing that the target for merger is not FACE but prevelar VAGUE. Elicited word lists and reading passages specifically included words from the vAGUE class under the prediction that they are lowered rather than raised, and merger may therefore occur between the three prevelars (BAG-BEG-VAGUE) in a separate subsystem from nonprevelars. 


\section{Regional distributions of prevelar raising}

Studies of prevelar raising and merger are relatively recent and mostly focus on BAG-raising. Three broad geographic surveys have found wide distributions of BAG-raising across the northern US and Canada. In the Atlas of North American English, Labov, Ash, and Boberg (2006:181-4) reported phonetic raising of BAG toward FACE in areas across the American north and into Canada, to the extent of merger with VAGUE in the Wisconsin-Minnesota area of the Upper Midwest. Boberg (2008) further investigated the pattern in Canada, finding more extensive raising in the western provinces than in the east. Similarly, participants who selfreported BAG-raising in Stanley's (2019a) massive online survey of North America were from northern regions, stretching from New England to the Pacific Northwest and throughout Canada, but concentrated most heavily in the center of this region, from the Upper Midwest and Northern Great Plains to the Canadian Prairies.

In phonetic studies of the Upper Midwest, Zeller (1997) first described BAGraising in Wisconsin, concluding that TRAP before voiced velars, both oral and nasal (BAG, HANG), merged with FACE at increasing rates over subsequent generations. However, Bauer and Parker (2008) and Benson, Fox, and Balkman (2011) challenged the notion that raised BAG was merged with nonprevelar DRESS or FACE in Wisconsin. Both studies included duration and formant measures at multiple time points, finding that the formant distributions of BAG often overlapped those of DRESS or even FACE at some points but not throughout their durations. Prevelar BAG variously began as low as TRAP or as high as DRESS, raising toward FACE over its duration (with the F1 of its offset reaching at most the F1 onset of FACE for Bauer \& Parker [2008]). In contrast, the formants of TRAP and DRESS changed less over their durations, often lowering or backing slightly rather than raising. Benson et al. (2011) concluded that, because all ages and genders raised BAG above DRESS, this was a firmly established pattern rather than a change in progress. Bauer and Parker (2008) also investigated a few VAGUE words, which patterned with BAG but not any nonprevelar vowel; they interpreted this as evidence that this tiny word class had been reanalyzed by speakers as belonging to the larger (and now raised) BAG class.

Stanley's (2019a) self-report survey also asked about BEG-raising, which was more variable between speakers but surprisingly more widely distributed across the continent, excluding the South. Interestingly, Stanley described the two BAGand BEG-raising processes as independent, showing that BAG-raising often occurred without much BEG-raising in the Upper Midwest, and BEG-raising occurred with much less BAG-raising in the Midland and West. However, in regions where both occur, they are likely related processes (Wassink \& Riebold, 2013), as in the Pacific Northwest.

\section{Prevelar raising in the Pacific Northwest}

The Pacific Northwest, including Washington, Oregon, and Idaho (and sometimes British Columbia and western Montana; see Figure 1), has been settled by English 


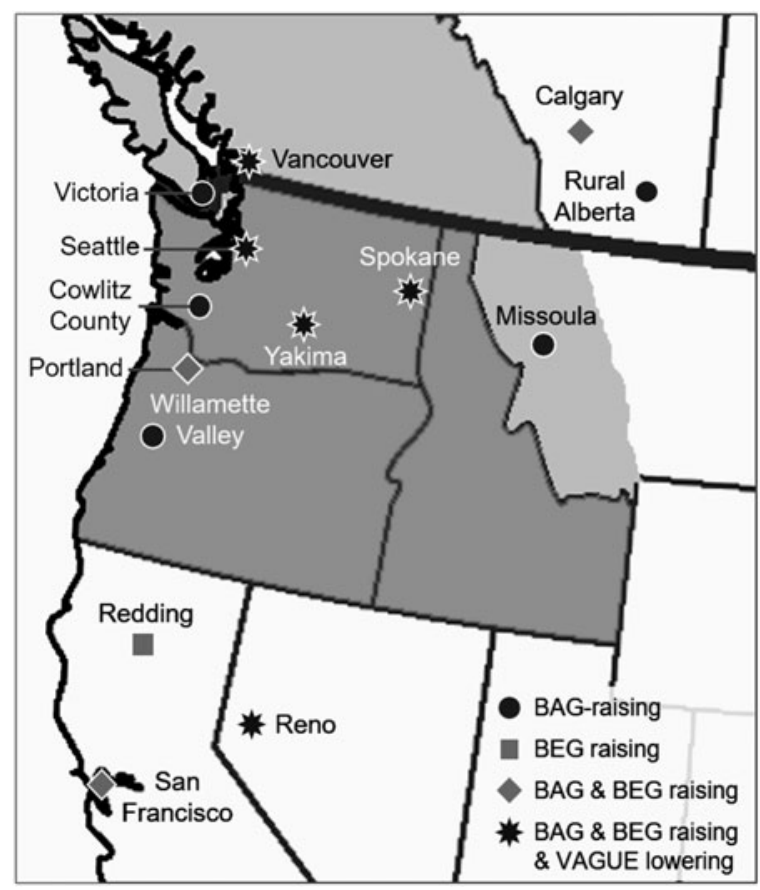

FIGURE 1. Sites in the Pacific Northwest (PNW) and surrounding areas where prevelar raising/merger has been reported. Dark shading: "core" PNW states (Washington, Oregon, Idaho); light shading: western Montana and British Columbia, sometimes considered part of PNW.

speakers for just over 200 years and is thus considered a relatively young dialect region. Reed's work on a Linguistic Atlas of the Pacific Northwest $(1952,1961)$ provided three observations of prevelar raising: /æ/ before the velar nasal in the word hang was raised to [e] (1952), /æ/ before /g/ in bag was canonically [æ] in about half of speakers and diphthongal but without a raised nucleus [æI] in the other half, and prevelar $/ \varepsilon /$ in egg and $k e g$ was often diphthongal, usually with the low $[\varepsilon]$ or $[\varepsilon \mathrm{I}]$ but occasionally the higher [e] or [eI] (1961). Aside from these early lexical observations, there was no further mention of prevelar raising in the Northwest until recent years.

In Seattle, Squizzero (2009) found that many speakers raised BEG toward FACE, and some also raised BAG to overlap with BEG or FACE. Gender patterns suggested that women might be more advanced in BEG-raising, while men might be more advanced in BAG-raising, especially in casual styles. In a larger study, Wassink $(2015,2016)$ reported widespread BAG- and BEG-raising advancing in apparent time across three generations of Seattleites, supporting its description as a longstanding feature that has continued to advance so that BAG and BEG words now rhyme for many speakers. Wassink and Riebold (2013) noted substantial 
individual variation in raising patterns among Seattle women and suggested a lexical frequency effect on BEG-raising, such that egg was raised most often, followed by leg and then peg.

Riebold (2015) expanded the study of Washington by focusing on four nonwhite ethnicities across three parts of the state (Seattle, rural Yakima Valley, small towns near Spokane). Similar to the white Seattleites, all groups raised both BAG and BEG and lowered VAGUE, creating widespread BEG-VAGUE merger and suggesting a limited influence of ethnicity on prevelar vowels. Overall, men produced more complete BEG-VAGUE merger, BAG-raising was highly variable, and middle-aged speakers showed more advancement in raising/merger than either older or younger generations. The slightly greater separation of BEG and VAGUE as well as the wide range of BAG heights found outside Seattle and in nonwhite speakers might suggest that prevelar raising spread outward from urban white Seattle, where BEG-VAGUE merger appeared to be complete, to other ethnicities and smaller towns across the Cascade Mountains, a culturally salient dividing line that separates the urban west from the agrarian east (Evans, 2013). However, style factors such as formality or social comfort during interviews may also play a role. Freeman $(2016,2019)$ found much less raising and merger among western Washingtonians in a laboratory setting than was found in any group participating in the sociolinguistic home interviews of prior studies. The least raising/merger occurred in the most formal tasks, further supporting Squizzero's (2009) conclusion that raising was more common in casual styles. Similar to Riebold (2015:83-8), raising/merger was least advanced in the youngest age group, suggesting young adults' reversal or avoidance of this otherwise advancing change.

Both BAG- and BEG-raising were also found among some speakers in a small study of Spokane in eastern Washington (Crosby \& Dalola, 2020), and limited evidence of BAG-raising has also been found among college students in Missoula in western Montana (Bar-El, Rosulek, \& Sprowls, 2017). In Alberta, Jones (2015) reported that college students in Calgary raised both BAG and BEG, with half raising BAG to merge with the raised BEG. Similarly, Rosen and Skriver (2015) reported high degrees of BAG-raising in rural southern Alberta, with advancement in apparent time led by young women, whose BAG was substantially higher than their DRESS.

Returning to the coast, Mellesmoen (2018) examined BAG, BEG, and VAGUE in Vancouver, British Columbia, finding that BAG was raising and VAGUE was lowering in apparent time, led by men. These merging prevelars overlapped BEG, but BEG was further front. Similarly, BAG has been reported as raised to the height of DRESS in nearby Victoria, BC, (Roeder, Onosson, \& D'Arcy, 2018). Swan (2016) compared raising across the US-Canada border, finding more BAGraising in Vancouver, BC than Seattle, but a similar propensity toward raising among speakers whose local pride was oriented toward traditional views of their cities as compared to those who valued recent changes in industry or wealth (Swan, 2020). Similarly, Stanley (2018a) reported more BAG-raising among residents of rural Cowlitz County in western Washington who expressed local 
pride and ties to traditional industry, while younger speakers in general showed less BAG-raising than speakers who were born before the collapse of the local timber industry.

Becker, Aden, Best, and Jacobson (2016) reported both BAG- and BEG-raising in the Portland area of Oregon, with speakers over age forty raising BAG more than younger speakers (as in Washington; Freeman, 2016, 2019; Riebold, 2015:83-8), and those with an "ideology of nonaccent" more likely to raise BAG than those who did not comment on their region being "accentless." In the Willamette Valley of western Oregon, McLarty, Kendall, and Farrington (2016) also found BAG-raising among middle-aged speakers but not young adults, suggesting that BAG-raising may be receding. However, they found little BEG-raising in either age group, in contrast to the prevalence of BEG-raising in Washington (Riebold, 2015; Wassink, 2015, 2016).

Moving south out of the Northwest, Fridland and Kendall (2017) and Gunter, Clayton, and Fridland (2017) found slight BEG-raising among some speakers in the Reno area of Nevada, with women leading, as well as VAGUE-lowering led by older men and some BAG-raising among middle-aged speakers, particularly women. However, they found no BAG-raising among younger speakers, similar to patterns in Washington and Oregon in which BAG was raised less in younger generations. Finally, D'Onofrio, Eckert, Podesva, Pratt, and Van Hofween (2016) noted some BEG-raising in Redding, California, and there may be evidence of slight BAG-raising and BEG-fronting in the San Francisco Bay area (Cardoso, Hall-Lew, Kementchedjhieva, \& Purse, 2016).

\section{Motivations for raising and merger}

Zeller (1997), Baker, Mielke, and Archangeli (2008), Purnell (2008), Wassink and Riebold (2013), and Gunter et al. (2017) described velar pinch - the simultaneous raising of F2 and lowering of F3 going into (or out of) a velar constriction-as the articulatory mechanism that may encourage the raising and fronting of $/ \mathfrak{x} /$ and $/ \varepsilon /$ before voiced velars. As the tongue dorsum raises to meet the velum, F2 rises and F3 lowers, creating the appearance of "pinching" on a spectrogram. At the same time, F1 also lowers, a movement involved in upgliding. With these glide-like articulations being elongated before voiced velars (compared to the voiceless velar $/ \mathrm{k} /$, whose anticipatory devoicing may also obscure a short velar pinch), phonemic monophthongs may be perceived as diphthongal and subsequently reanalyzed as the nearest phonemic diphthong in their path, /e/, which then reinforces the raised and diphthongal production (Bauer \& Parker [2008], following Ohala's [2003] perception-based model of sound change), potentially leading to phonological merger.

Merger violates the preference of phonological systems to maintain distinctions (Labov, 1994:313-4), but there are very few distinctions between the prevelar word classes (Stanley, 2019b). vAGUE is an extremely tiny class. It contains only a handful of common words (e.g., bagel, vague, plague, pagan, flagrant, fragrant, vagrant) and a few proper names and borrowings (e.g., the Hague, Sprague, Craig), almost 
none of which form minimal pairs with words in either the BEG or BAG class. BEG has larger membership but is also small and forms few minimal pairs with the much larger BAG class. Even fewer BAG-BEG pairs exist in which both members have high lexical frequency and are confusable in context (e.g., bag-beg, lag-leg). In short, the need to maintain distinction is absent, and while this does not necessarily motivate merger (Zeller, 1997), it does not impede it, either (Wedel, Kaplan, \& Jackson, 2013). Thus, language-internal forces promoting merger, such as the number and closeness of phonetic and perceptual features in common (Labov, 1994:327-9), may take precedence.

\section{Hypotheses}

This investigation was organized around four hypotheses that sought to characterize prevelar raising, its role in a merging prevelar subsystem, and patterns of social differentiation in this PNWE change in progress.

Hypothesis 1. BEG-VAGUE merger: BEG is raised and VAGUE is lowered so that BEG and VAGUE are merged at a point between DRESS and FACE. Even in studies that have not considered vaGUE, BEG is shown lower than FACE (e.g., Squizzero, 2009), making it difficult to support claims of merger of BEG with FACE. However, if vaGUE lowers, it is clearer that the target for prevelar merger is not the same location as FACE.

Hypothesis 2. BAG-raising: BAG raises to overlap with BEG and/or VAGUE. If Hypothesis 1 is also supported and vaGUE is lowered, the raising of BAG to overlap BEG and VAGUE at a location between DRESS and FACE would support a three-way prevelar merger while remaining consistent with previous findings that BAG does not raise as high as FACE.

Hypothesis 3. Diphthongal prevelars: The three prevelars form a subsystem of upgliding diphthongs. The short/lax front vowels /æ, $\varepsilon /$ have been observed with glides before velars in PNWE (Reed, 1961; Wassink \& Riebold, 2013), suggesting that BAG and BEG must join the long/diphthongal /e/ to complete a three-way merger. However, if FACE in PNWE is fairly monophthongal (Ingle, Wright, \& Wassink, 2005; Wassink, 2015), prevelar vAGUE must also become a rising diphthong to obtain full merger with a diphthongal BEG and BAG.

Hypothesis 4. Social differentiation: Prevelar patterns differ across age and gender groups, indicative of change in progress. Raising may be advancing in apparent time toward three-way merger, perhaps with one gender leading. Within or across age groups, men and women may treat BAG and BEG differently, suggesting differing social values for the two types of raising.

\section{METHODS}

\section{Participants}

Participants were twenty white native English speakers who had spent all or most of their childhoods in the Seattle metropolitan area, divided evenly by gender and age group. Middle-aged speakers (five men, five women) were age 37-62 at the time of 
TABLE 1. Target words measured from the reading passage and word list

\begin{tabular}{llll}
\hline \hline Environment & $/ \mathfrak{x} /$ & $/ \varepsilon /$ & $/ \mathrm{e} /$ \\
\hline \multirow{2}{*}{$\mathrm{C}$ (plain) } & bad & bed & bait \\
& dad & dead & pace \\
hatch & test & bagel \\
& bag $/ \mathrm{g} / \mathrm{\text {zig-) }}$ & egg & vague \\
& magnet & peg & pagan \\
& lag & leg & \\
& nag & leggings \\
& brag & negative & \\
& drag & regular & \\
& dragon & & \\
& &
\end{tabular}

recording in 2013, and Younger speakers (five men, five women) were age 18-36. Most identified as middle-class, with a few indicating working-class upbringings, and most of their parents also grew up in the region, making them second or third generation Northwesterners.

\section{Elicitation procedures and materials}

As part of a larger project on Pacific Northwest English (see Wassink, 2015, 2016), recording sessions involved several tasks, including a group sociolinguistic interview with friends or family, individual linguistic tasks, a reading passage, and three repetitions of a word list using the carrier phrase "Write __ today." Participants were recorded in their homes or study rooms in public libraries using a Samson Zoom H4n Pro Handy Recorder with both built-in microphones, creating 32-bit stereo recordings with $44.1 \mathrm{kHz}$ sampling rates. Interview sessions lasted one to three hours, and all participants were compensated \$15.

A subset of twenty-seven target words from the reading passage and word list was selected for analysis (Table 1), yielding 1-5 repetitions of each target from each speaker, for a total of 2,556 measured vowels. Targets included all measurable utterances (tokens) of words with each non-high front vowel before $/ \mathrm{g} /$. For comparison, all measurable tokens of a set of monosyllabic words representing each non-high front vowel before a coronal obstruent $(/ \mathrm{t}, \mathrm{d}, \mathrm{t} f, \mathrm{~s} /)$ were selected. Due to the sparsity of prevelar words, those with liquids before the vowel were not excluded.

\section{Analysis procedures}

Vowel measurements. Transcripts of each speaker's reading passage and word list were forced-aligned using the Penn Phonetics Lab Forced Aligner (P2FA, Yuan \& Liberman, 2008) to create phone-level Praat TextGrids. All vowel boundaries were then hand-corrected in Praat (Boersma \& Weenink, 2013) following procedures in Freeman (2010). Vowel formants (F1, F2, F3) were measured at $20 \%, 50 \%$, and $80 \%$ of vowel duration using a Praat script that automatically located and measured all target words. The formant range was set to $0-5500 \mathrm{~Hz}$ 
with a window length of $25 \mathrm{~ms}$ and dynamic range of $30 \mathrm{~dB}$. The number of formants was set per speaker (four, five, or six) based on the best fit of the LPC formant tracker to the majority of their target tokens, as observed visually during hand-correction of phone boundaries. Automatic formant measurements that fell more than two standard deviations from their respective means (within-formant, within-vowel, within-speaker) were verified or corrected by hand; consequently, about a quarter of all tokens were reviewed manually.

Speaker normalization. Since individual speakers have differing formant ranges, pooling of raw Hertz values can obscure meaningful differences (or similarities) between speakers. To compare all speakers together, formant measures from speakers' entire vowel spaces were first normalized using the Nearey 2 formula in the NORM Vowel Normalization Suite (Thomas \& Kendall, 2010) before only the non-high front vowels were plotted. This method is vowel-extrinsic and formant-extrinsic and has been found to preserve sociolinguistic differences while neutralizing the effects of physiological differences between speakers (Adank, Smits, \& van Hout, 2004).

Vowel overlap. For visualization of vowel overlap, Nearey-normalized midpoint distributions were plotted with ellipses representing two standard deviations around the distributional means in $\mathrm{F} 1 \mathrm{xF} 2$ space in $\mathrm{R}$ ( $\mathrm{R}$ Core Team, 2020) using the phonR package (McCloy, 2016). The similarity of vowel distributions was quantified using Pillai scores. The Pillai-Bartlett statistic (shortened to 'Pillai score' by Hay, Warren, \& Drager [2006]) is an output of a multivariate analysis of variance (MANOVA), which indicates a degree of distinction between distributions while taking into account two or more dependent variables simultaneously. Pillai scores range from zero to one with lower scores indicating greater similarity between distributions. They have been used in studies of both mergers and shifts (e.g., Hall-Lew, 2009; Hay et al., 2006) and have been found to model the degree of overlap or distinction better than other methods due to their ability to account for multiple dimensions, skewed distributions, unequal densities, and sparse data (Hall-Lew, 2010; Kelley \& Tucker, 2020; Nycz \& Hall-Lew, 2014). In the present study, Neareynormalized F1 and F2 midpoint values were entered as the dependent variables, with Vowel class as the independent variable and Speaker and Word as random effects.

While very large Pillai scores may support a categorization of vowel distributions as statistically distinct, there is no standard cutoff to determine when a smaller Pillai score indicates merger versus partial overlap (Stanley, 2019c). Thus, linear mixed-effects (LME) models were used in conjunction with Pillai scores to further characterize vowels as merged or distinct. Models were performed in R using the lme4 package (Bates, Mächler, Bolker, \& Walker, 2015) with separate models for each formant (Nearey-normalized F1, F2) at midpoint, with Speaker and Word as a random effects and Vowel class as a fixed effect. For both the Pillai scores and LMEs, models compared each pair of prevelars for merger, as well as BAG versus TRAP to assess the presence of BAG- 
raising, for all speakers pooled and for each age/gender group. Pillai scores were also calculated for each speaker between BAG and VAGUE to quantify individual differences in BAG-raising.

Trajectory modeling. Changes in formant values over vowel duration were visualized via smoothing-spline analyses of variance plots (SSANOVA; Nycz \& De Decker, 2006; see also Fruehwald, 2010) using the gss R package (Gu, 2014). The model uses Gaussian process regression to infer a separate probabilistic best-fit curve for each formant within each vowel class to connect the mean values at each measured time point $(20 \%, 50 \%, 80 \%$ of vowel duration). This plotting method presents trajectory information more accurately than vector-based representations, which connect measured time points with straight lines. The resulting plots resemble formant traces on a spectrogram with 95\% confidence intervals around the best-fit mean curves. The confidence intervals are akin to the ellipses of two standard deviations seen in midpoint F1xF2 plots, and by convention, if the confidence intervals of two vowels do not overlap, their distributions are considered separate. Of the total 2,556 tokens, eighty-nine were excluded from this analysis, because their onset measurement point (at $20 \%$ of vowel duration) fell within the aspiration following an aspirated consonant $(/ \mathrm{p}, \mathrm{t}, \mathrm{k} /)$.

\section{RES ULTS}

\section{Formants at midpoint}

BEG-VAGUE merger (Hypothesis 1). There is strong evidence to support Hypothesis 1, the overlap of BEG and VAGUE at a point between their plain counterparts, DRESS and FACE. Figure 2 shows the non-high front F1xF2 vowel space for all speakers with ellipses of two standard deviations around each vowel's Nearey-normalized mean at midpoint. All panels show the same distributions with different portions shaded to highlight relevant comparisons. Table 2 lists the corresponding Pillai scores. As seen in Figure 2b, BEG and VAGUE (dark shading) overlap almost entirely (Pillai score: .05) at a location between their plain counterparts (light shading), which are separate (Pillai score: .85). Linear mixed-effects models further support a determination of BEG-VAGUE merger, as they did not distinguish BEG and VAGUE at midpoint in either F1 or F2 (see Appendix Table A for all statistics).

BAG-raising (Hypothesis 2). Figure 2c highlights how prevelar BAG (dark shading) has a raised and wider distribution than plain TRAP (light shading). Figure $2 \mathrm{~d}$ highlights all three prevelars, with BAG showing moderate overlap with both BEG and VAGUE as well as plain TRAP (Pillai scores of .45, .43, .41; Table 2). (However, this partial overlap does not constitute merger: linear mixed-effects models showed that BAG is distinct from BEG-VAGUE as well as plain TRAP in both F1 and F2; Appendix Table A). Compare this to the amounts of overlap between plain vowels: looking across columns in Table 2, each pair of vowels has a 
F2
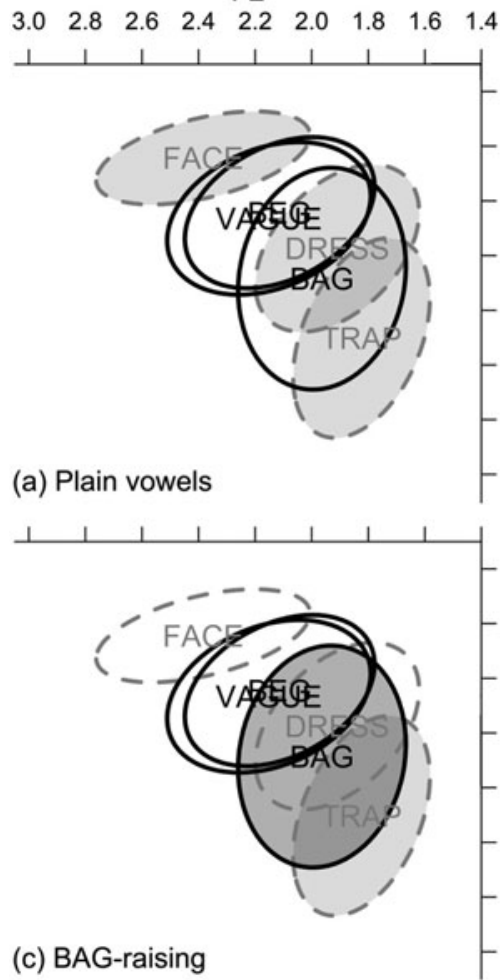

F2

$\begin{array}{lllllllll}3.0 & 2.8 & 2.6 & 2.4 & 2.2 & 2.0 & 1.8 & 1.6 & 1.4\end{array}$

(b) BEG-VAUGE merger

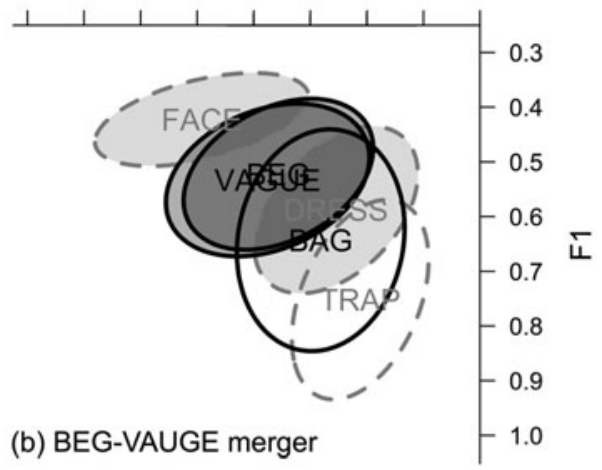

(d) Prevelars

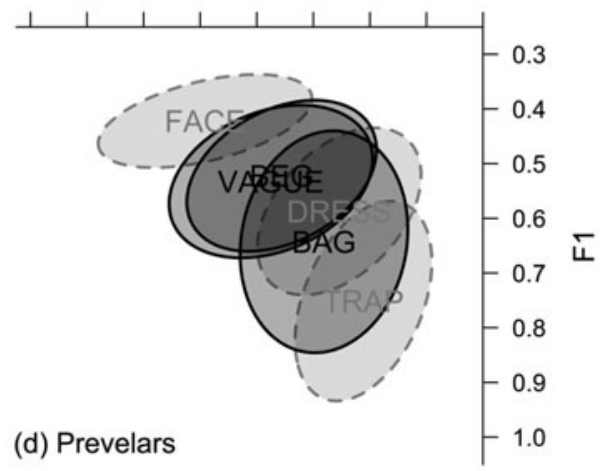

FIGURE 2. F1xF2 Nearey-normalized midpoint plot of all speakers pooled $(n=20)$. All panels show the same distributions, the means for each vowel with ellipses of 2 SD. Figure 2a highlights the plain vowels (light shading). Figure $2 \mathrm{~b}$ highlights the positions of prevelar VAGUE and BEG (dark shading) compared to plain FACE and DRESS (light shading). Figure 2c highlights the position of BAG (dark shading) compared to TRAP (light shading). Figure $2 \mathrm{~d}$ highlights all three prevelars (dark/solid) compared to their plain counterparts (light/dashed).

TABLE 2. Pillai scores between vowels before / $g / v$ s other consonants (_C) for all speakers pooled $(\mathrm{n}=20)$ and each age/gender group $(\mathrm{n}=5$ each $)$. Lower numbers indicate greater overlap

\begin{tabular}{|c|c|c|c|c|c|c|c|c|c|c|}
\hline & \multicolumn{2}{|c|}{ All } & \multicolumn{2}{|c|}{ Middle men } & \multicolumn{2}{|c|}{$\begin{array}{l}\text { Middle } \\
\text { women }\end{array}$} & \multicolumn{2}{|c|}{$\begin{array}{l}\text { Younger } \\
\text { men }\end{array}$} & \multicolumn{2}{|c|}{$\begin{array}{l}\text { Younger } \\
\text { women }\end{array}$} \\
\hline & _C & -g & _C & -g & - C & -g & -C & -g & _C & _g \\
\hline$\varepsilon-\mathrm{e}$ & .85 & .05 & .91 & .03 & .87 & .07 & .87 & .01 & .91 & .07 \\
\hline $\mathfrak{x}-\varepsilon$ & .60 & .45 & .66 & .28 & .62 & .45 & .70 & .61 & .67 & .62 \\
\hline $\mathfrak{x}-\mathrm{e}$ & .91 & .43 & .95 & .19 & .93 & .44 & .94 & .56 & .95 & .60 \\
\hline æ-æg & \multicolumn{2}{|c|}{.41} & \multicolumn{2}{|c|}{.77} & \multicolumn{2}{|c|}{46} & \multicolumn{2}{|c|}{.28} & \multicolumn{2}{|c|}{.36} \\
\hline
\end{tabular}


F2

$\begin{array}{lllllllll}3.0 & 2.8 & 2.6 & 2.4 & 2.2 & 2.0 & 1.8 & 1.6 & 1.4\end{array}$
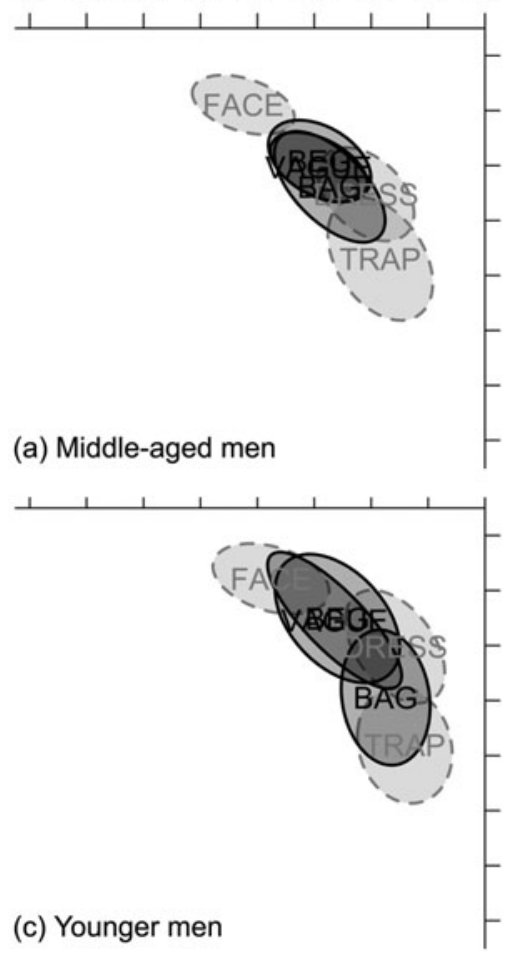

F2
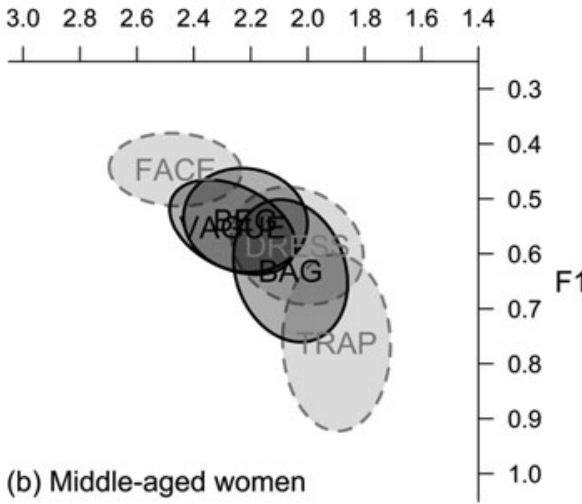

(d) Younger women

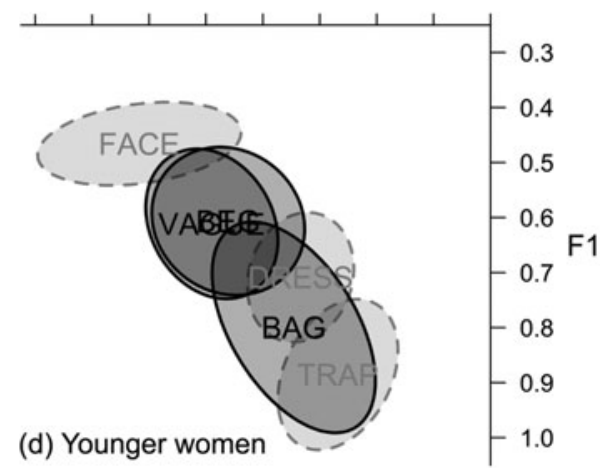

FIGURE 3. F1xF2 Nearey-normalized midpoint plots for each age/gender group ( $n=5$ each). Ellipses show 2 SD around the mean of each vowel. Dark shading/solid lines: prevelars, light shading/dashed lines: plain vowels. Note that with nearly identical means, the labels for VAGUE and BEG overlap.

higher Pillai score in plain contexts than before /g/. DRESS and FACE are separate; BEG and VAGUE are merged. Prevelar $/ \mathfrak{x} /$ must raise farther than $/ \varepsilon /$ does in order to decrease the distance between them, and as BAG raises away from TRAP, it approaches the more distant VAGUE. With speakers separated by age and gender, shown in Figure 3, it is clear that differing treatments of BAG contribute to its wider distribution.

Social differentiation (Hypothesis 4). Figure 3 shows the prevelar vowel space for each age/gender group. As in Figure 2d, the prevelars are shaded darkly to highlight the areas of overlap between them as well as their positions relative to their plain counterparts. For every speaker group, BEG and vAGUE have nearly identical distributions with very high overlap (Pillai scores near 0; Table 2). Their location is clearly centered between FACE and DRESS (which are separate with Pillai scores near .90), extending to overlap each plain vowel almost 
equally. Linear mixed-effects models confirmed that BEG and VAGUE are indistinguishable for all groups in both F1 and F2 (Appendix Table A). These results are consistent with the pooled data that these two prevelars overlap nearly entirely at midpoint, centered between their plain counterparts.

In contrast, the position of BAG differs between the groups. In all groups, BAG is raised from TRAP, but its height and range differ between groups. Most striking is the difference between middle-aged men (Figure 3a), whose BAG distribution displays high overlap with BEG-VAGUE but not TRAP (Pillai scores: .28, .19 versus .77; Table 2), and younger women (Figure 3d), whose wide distribution of BAG partially overlaps both BEG-VAGUE $(.62, .60)$ and, to a greater extent, its plain counterpart TRAP (.36). Linear mixed-effects models did not distinguish between the middle-aged men's BAG, BEG, or VAGUE in F2, meaning that all three prevelars are equally front, but the slightly expanded distribution of BAG maintained some distinction from BEG-VAGUE in F1. Models also confirmed that BAG is distinct from TRAP in both F1 and F2 for both these groups (Appendix Table A).

Middle-aged women show an intermediate configuration (Figure 3b), with BAG centered at about the height of DRESS and showing moderately high overlap with BEG, VAGUE, and TRAP (Pillai scores: .45, .44, .46; Table 2). Like younger women, younger men (Figure 3c) center BAG a bit lower than DRESS and overlap BEGVAGUE moderately $(.61, .56)$ while maintaining high overlap with TRAP (.28). For both these groups, linear mixed-effects models showed that BAG is distinct from BEG, VAGUE, and TRAP in both F1 and F2 (Appendix Table A).

Individual differences. With a small number of speakers in each age/gender group, individual differences can make substantial contributions to group distributions. Figure 4 illustrates individual variation in BAG-raising with plots of each speaker's prevelars (dark) and plain vowels (light), arranged by age/gender group (rows) and ordered within each group from most to least BAG-raising, as quantified by the Pillai score between the speaker's BAG and VAGUE distributions. Although there is substantial variation within each group, more of the older speakers show greater degrees of raising. In examining the F1 heights of BAG in conjunction with the Pillai scores, two middle-aged men show full three-way merger with BEG-VAGUE, and the other three could be described as showing nearmerger or a shift toward BEG-VAGUE. Three middle-aged women show this nearmerger, one has a shift, and one is not raised at all. Both younger groups have one merged speaker, two with expanded (men) or shifted (women) BAG distributions, and two without raising.

In short, middle-aged men are advanced in BAG-raising, almost to the point of three-way merger with BEG-VAGUE. While middle-aged women are less advanced, most do raise BAG, but most younger speakers show much less raising.

\section{Trajectory (Hypothesis 3)}

Vowels with similar formant frequencies at midpoint may differ in the location, direction, or slope of their trajectories. Offglides are often visualized in an F1xF2 plot with arrows representing the direction of change, like Figure 5, 


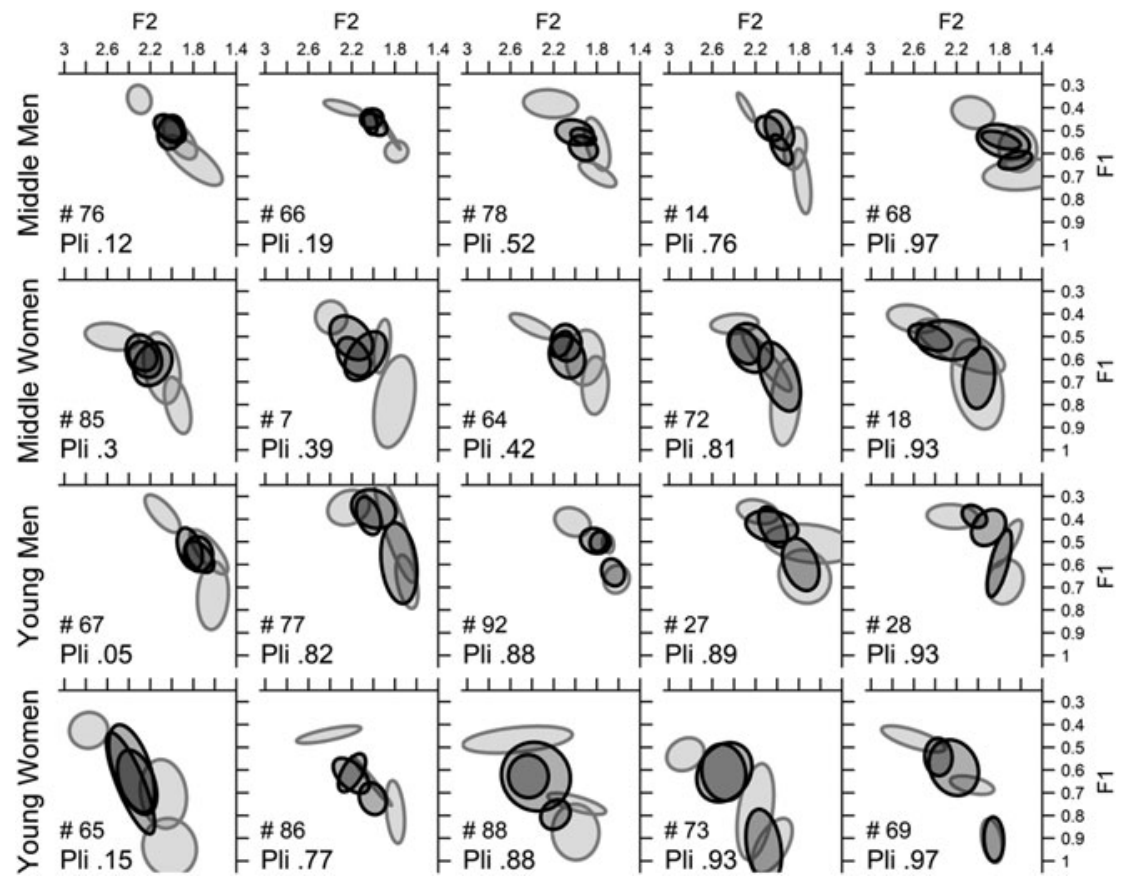

FIGURE 4. F1xF2 Nearey-normalized midpoint plots for each speaker $(n=20)$, ordered by most to least BAG-raising within each age/gender group row, as measured by the speaker's Pillai score between BAG and vAGUE (abbreviated Pli). Dark: prevelars; light: plain vowels.

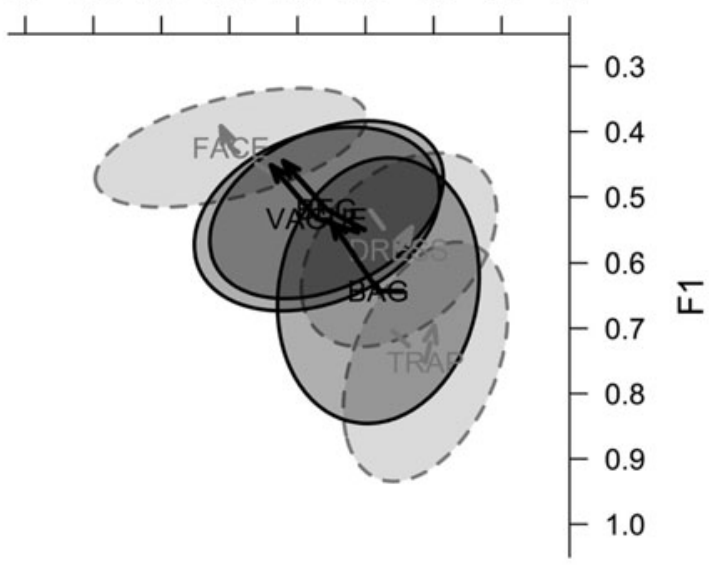

FIGURE 5. F1xF2 Nearey-normalized plot with diphthong trajectories (20-50-80\% of vowel duration) and ellipses of 2 SD around midpoint means, all speakers pooled $(n=20)$. Dark/solid: prevelars; light/dashed: plain vowels. 
(a) BEG-VAGUE merger

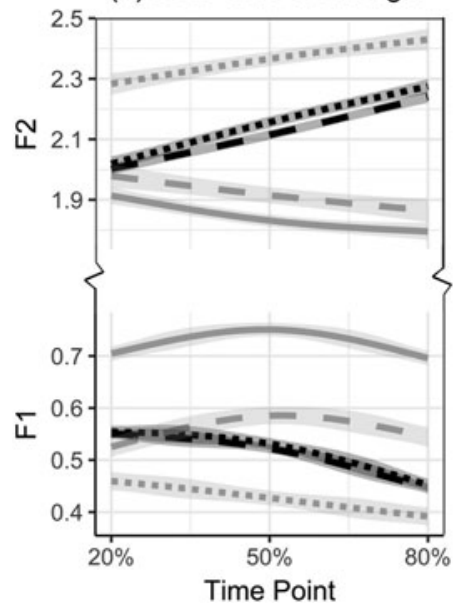

(b) BAG-raising

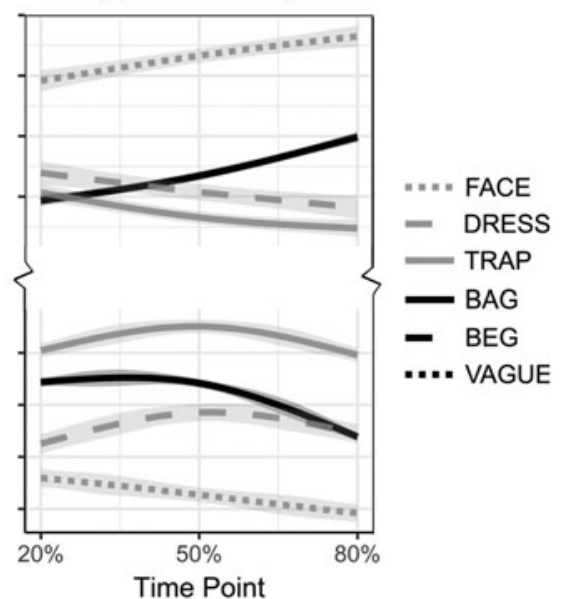

FIGURE 6. SSANOVA plots of Nearey-normalized formant change over vowel duration, $95 \%$ confidence intervals (shading) around means (lines), all speakers pooled $(n=20)$. (6a) BEGVAGUE merger (overlapping dark dashed/dotted lines) and (6b) BAG-raising (dark solid lines) are each plotted in comparison to plain vowels (light lines). Note: the F2 range is shown at twice the scale of the F1 range to mirror the same convention in plotting F1xF2 (as in Figures 2-5).

which shows arrows connecting mean vowel measurements at 20-50-80\% of vowel duration, revealing all three prevelars as rising diphthongs. However, the arrows only roughly simulate the path of formant change by connecting measurement time points with straight lines. To more closely model the path of change, smoothing spline analyses of variance (SSANOVA) were performed and the results plotted in Figure 6. SSNAOVA plots show mean formant values at all measured time points with a best-fit curve connecting them. With an appearance similar to that of formant traces on a spectrogram, formant measures are indicated on the vertical axis and time point of vowel duration across the horizontal. Confidence intervals of $95 \%$ around the means are represented by shading that, in this data set, closely follows the mean lines. By convention, if the confidence intervals around two means do not overlap, the distributions differ significantly.

Figure 6a shows that BEG and VAGUE (dashed and dotted dark lines) overlap almost completely all along their trajectories and are indistinguishable in F1. Interestingly, their onsets overlap the onset of monophthongal DRESS (light dashed lines), but they move about halfway to FACE (light dotted) at midpoint and offset. This is slightly greater change over vowel duration than the higher FACE, which does not appear to be as monophthongal as has been found in previous work on Seattle English (Ingle et al., 2005; Wassink 2015). Also of note is the position and trajectory of BAG (Figure 6b, dark solid lines) - it is considerably raised overall, with a lower F1 than monophthongal TRAP (light solid) and an upgliding trajectory that parallels BEG-VAGUE. This trajectory 
(a) Middle-aged men

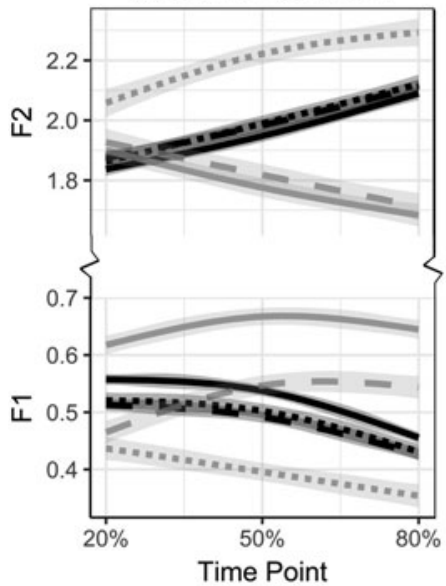

(c) Younger men

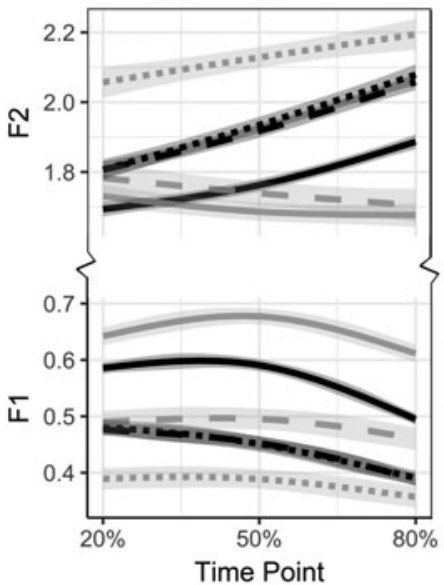

(b) Middle-aged women

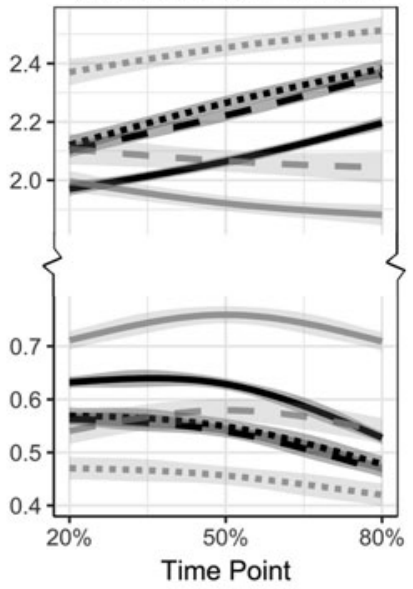

$\ldots$ FACE

- DRESS

(d) Younger women

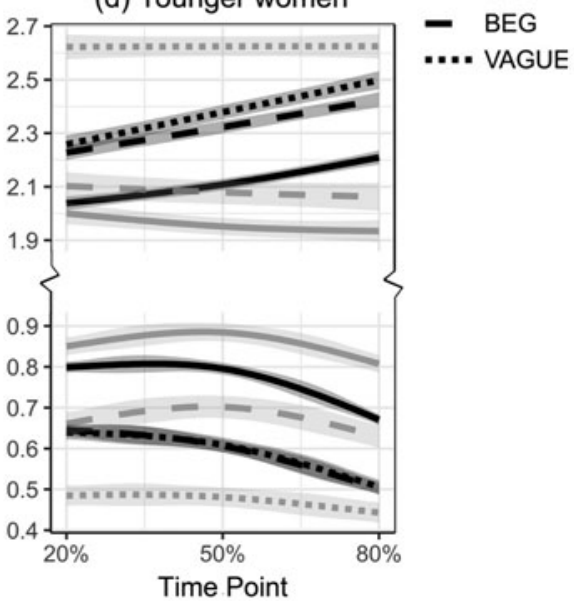

FIGURE 7. SSANOVA plots of Nearey-normalized formant change over vowel duration for each age/gender subgroup ( $n=5$ each), 95\% confidence intervals (shading) around means (thick lines). Note: the scales for each formant are expanded to fit the same vertical distances for ease of visual pattern comparison. The primary difference is in the location of BAG (dark solid lines).

information adds an important dimension to the midpoint data above: while BAG overlaps DRESS at midpoint, it is distinguished by beginning lower (as seen by its higher F1 at onset) and ending more front (as seen by its divergence from DRESS in F2). This evidence of formant change throughout vowel duration supports Hypothesis 3, that all three prevelars are upgliding diphthongs.

Social differentiation (Hypothesis 4). As with the midpoint data, all speaker groups overlap BEG and VAGUE almost entirely (Figure 7) but differ in their 
treatment of BAG, with middle-aged men displaying the most striking pattern (Figure 7a). For them, BEG and VAGUE are completely merged along their entire trajectories (black dashed and dotted lines with overlapping confidence intervals), and BAG (dark solid lines) closely parallels BEG-VAGUE with an identical F2 and an F1 that nearly "catches up" to the higher prevelars' offglides, passing the height of DRESS at midpoint (light dashed). In contrast, BAG for the other speaker groups is farther back (with a lower F2) than BEG-VAGUE, and it is a bit lower than BEG-VAGUE (higher F1) among middle-aged women (Figure 7b), about halfway to TRAP for younger men (Figure 7c), and closer to TRAP for younger women (Figure 7d), a pattern suggesting that women may lead in reversing BAG-raising in apparent time.

To summarize the trajectory patterns, all three prevelars have upglides, as does FACE. All speaker groups show steeper slopes for the prevelar diphthongs than for the plain vowels, indicating a more diphthongal characterization for prevelars which may help to differentiate them from nearby plain vowels. All age/gender groups show BEG and VAGUE beginning at or near the onset of the monophthongal DRESS but ending higher and more front. All groups show BAG beginning near the monophthongal TRAP and then rising and fronting, crossing the trajectory of DRESS near midpoint. Thus, although BAG and DRESS overlap substantially at midpoint, they appear to be distinguished by their trajectories, with BAG beginning lower but ending higher.

\section{DISCUSSION}

\section{Main findings}

Support was found for all four hypotheses. Hypothesis 1 (BEG-VAGUE merger) was strongly supported: for all speaker groups, BEG and VAGUE were merged all along their trajectories, positioned between the nonprevelar DRESS and FACE. Earlier work on Pacific Northwest English found BEG to be raised, but, without tokens of VAGUE, the reference point was nonprevelar FACE (Squizzero, 2009; Wassink, 2015, 2016; Wassink \& Riebold, 2013). This is an important contribution of the current study, showing that BEG-raising is indeed part of a merger - not with FACE but instead with prevelar VAGUE, which lowers to join BEG rather than raising, as might be predicted following the coarticulatory explanation involving velar pinch. It follows that the tiny vaGUE word class may have been reinterpreted as belonging to the larger and phonetically proximal raised BEG class. A similar argument has been proposed in other regions: in both Wisconsin and British Columbia, VAGUE was found to be lowered from FACE, but it patterned more closely with raised BAG than raised BEG, suggesting that the few VAGUE words have been reanalyzed as belonging to the larger BAG class (Bauer \& Parker, 2008; Mellesmoen, 2018). These regions were both identified by Stanley (2019a) as having more BAG-raising than BEG-raising, while the American Northwest has more BEG-raising than BAG-raising. Thus, across regions, it is 
likely that VAGUE words have been reanalyzed as belonging to their nearest raised prevelar neighbor, which in Washington is BEG.

Regarding Hypothesis 2 (BAG-raising), BAG was found to raise for all speaker groups, overlapping the other prevelars as predicted, but only to the predicted height of BEG-VAGUE for middle-aged men. Their BAG distribution extended a bit lower than BEG-VAGUE, indicating incomplete three-way merger. As expected, BAG did not raise to the height of FACE for any speaker, supporting the theory that the target for BAG-raising is possible merger with the higher and already merged prevelars BEG-VAGUE, not FACE.

Hypothesis 3 (diphthongal prevelars) was also strongly supported: all prevelars showed clear upglides as they raised and fronted over their durations. This especially helps separate prevelar BAG and BEG from their monophthongal plain counterparts, and it contributes to the clarity of the spectral merger between BEG and VAGUE. The spectral separation of prevelars from FACE and the addition of an upglide to BAG (even when it is spectrally distant from upgliding phonemes as possible merger targets) further support the theory that these three prevelars form a distinct subsystem from their plain counterparts.

Offering partial support for Hypothesis 4, social differentiation was apparent, but only for BAG-raising. BEG-VAGUE merger was constant across speaker groups (similar to Riebold [2015:80-115] for other parts of Washington), but BAG was raised highest for middle-aged men, followed by middle-aged women, and then younger speakers. This is contrary to the prediction that younger speakers would show more raising (suggested by Wassink [2015, 2016] and Wassink \& Riebold [2013]) but in line with similar patterns found in other parts of the Northwest where there was also less BAG-raising in younger speakers than middle-aged groups (Riebold, 2015:83-8 for Washington; Becker et al., 2016 and McLarty et al., 2016 for Oregon). Gender differentiation was strong in the middle-aged generation, with men showing greater BAG-raising than women (as in Squizzero, 2009), but it was less clear in the younger generation. This could indicate retraction over time led by women or a social association with BAG-raising that younger speakers (particularly women) wish to avoid (Freeman, 2016). Other work with Seattle women found that BAG was raised higher among middle-aged speakers than among their parents' generation (Wassink \& Riebold, 2013), making the possibility of reversal in just one more generation quite surprising. However, if some speakers in the younger generation continue to advance, the social differentiation driving such a divide must be oriented toward something more specific than age, and it is possible that BAG-raising has taken on social salience and stigma only in recent years. In contrast, the stability of BEG-VAGUE merger across groups is indicative of a completed change, one that appears to have proceeded largely without comment or stigma.

\section{Other factors to consider}

Other social factors should be examined in future work. Riebold (2015) found similar patterns in several areas of Washington but no substantial effect of 
ethnicity, urbanness, local network strength, or location in the state, further indicating that the social relationship to BAG goes beyond demographics. For example, in nearby areas of rural western Washington and urban British Columbia, Stanley (2018a) and Swan (2020) found relationships between BAGraising and the source of speakers' local pride, with more raising among those who valued traditional local lifestyles compared to those who preferred recent changes in local industry. A similar local-values factor may be at work in Seattle, where industry has changed in recent decades, with major employers shifting from logging/paper processing and airplane manufacturing to computer software and technology. Globalization and increasing connectedness in communication may also contribute to younger generations' avoidance of salient local dialect features in favor of "accentless" national norms (Chambers, 2000; Milroy, 2002). Formality, style, and discourse factors may also contribute. Only tokens from formal reading tasks were reported here, but other work has found greater raising in more casual tasks and less prevelar raising and merger in more formal lab settings (Freeman, 2016, 2019; Squizzero, 2009), so the current results could represent a midpoint on a continuum of speakers' repertoires.

As an incomplete change in progress, language-internal factors might also shed light on the direction or mechanism of change. Some prior work reported lexical effects for both BAG-raising (Stanley, 2018b) and BEG-raising (Gunter et al., 2017; Wassink \& Riebold, 2013), and Stanley (2018b, 2019b) reported that BEGraising is more common in borrowings and less common before sonorants. However, lexical effects were not apparent in the current study, and given the small class memberships of BEG and especially VAGUE, further clarity on language-internal factors may be difficult to achieve.

Duration may also contribute to either merger or distinction among prevelars. In a preliminary exploration of the present data, prevelars were similar in duration to their plain counterparts, with DRESS and BEG remaining shorter. Thus, duration might be a barrier to full BEG-VAGUE merger, and for speakers who spectrally merge BAG with BEG-VAGUE, the similar durations of BAG and VAGUE may reinforce their merger while maintaining the shorter BEG as distinct. This could be examined in phonemic perception tasks.

Discussion of merger is incomplete without consideration of perception as well as production. In a pseudolexical decision task of synthetic stimuli, Northwesterners in Freeman (2019) categorized raised variants as coming from the words beg or bagel but rarely bag, even when they produced raised BAG themselves. Among BAG-raising Canadians and nonraising Americans attending college in Toronto, where BAG-raising is common, Sullivan (2020) found a similar lack of connection between individual production and perception in a lexical decision task involving resynthesized nonce words. Both studies concluded that raisers and nonraisers alike relied more on their experience of hearing raising in the community than on their own production. Freeman (2019) further posited that younger listeners included older speakers in their speech community of reference, aware that some (mostly middle-aged and older) people raise BAG even if they themselves avoid it, but older listeners did not accurately 
incorporate into their perceptual representations the raising they have heard from their children's (now middle-aged) generation. Both studies used synthetic stimuli with flat formant slopes and fixed duration, leaving much room for future work on the contributions of duration, glide length, and other understudied features of natural productions to the determination of prevelars as merged or distinct.

\section{CONCLUSION}

This examination of the speech of twenty white Seattleites in formal reading tasks found that prevelar BEG was raised and VAGUE was lowered so that BEG and VAGUE were spectrally merged at a position between their nonprevelar counterparts DRESS and FACE. This held all along their trajectories, which had raising and fronting upglides. Prevelar BAG was raised and upgliding for all speakers, but its height varied considerably between groups, showing social differentiation by age and gender: middle-aged men produced nearly complete three-way merger with BEG-VAGUE, while middle-aged women showed less raising and overlap with BEG-VAGUE, and younger speakers showed the least raising and little overlap with BEG-VAGUE, perhaps suggesting a (currently unidentified) social meaning they wished to avoid.

Taken together, the results of this study support a model of the low-front prevelar subsystem as separate from its plain counterparts. Velar pinch provided phonetic motivation for short/lax /æ, $\varepsilon /$ to become rising diphthongs before voiced velars (BAG, BEG), prompting them to be reanalyzed as the nearest rising diphthong, /e/ (vague). At the same time, because the vague class is so small, its members were reassigned to the now-adjacent raised BEG class (Gunter et al., 2017). Neither BEG nor VAGUE had to migrate very far phonetically to merge, meaning that the changes in both production and perception were not large and may have completed without much notice. Diphthongal BAG had farther to raise in phonetic space to be reanalyzed as VAGUE, and its lexical membership is larger, so it may therefore become more phonetically and socially meaningful over time as it raises higher toward the already-merged BEG-VAGUE.

\section{ACKNOWLEDGMENTS}

Data collection was supported by NSF grants BCS-0643374 and BCS-1147678 (PI Alicia Wassink). Portions of the results were reported in a previous working paper (Freeman, 2014) and at various conferences. Special thanks to Alicia Wassink for her guidance on this project.

\section{NOTES}

1. Compare Stanley's (2019b) mention of the slang shortening preggo (pregnant) and Italian borrowing/brand name Prego as a possible BEG-VAGUE minimal pair.

2. In addition, preliminary analysis of high-front prevelars (EAGLE, BIG) indicates that these are not involved in the proposed prevelar subsystem: they are not substantially shifted, and they have much shorter offglides than the merging prevelars, as might be expected due to coarticulation alone. 


\section{REFERENCES}

Adank, P., Smits, R., \& van Hout, R. (2004). A comparison of vowel normalization procedures for language variation research. Journal of the Acoustical Society of America 116(5):3099-3107.

Baker, Adam, Mielke, Jeff, \& Archangeli, Diana. (2008). More velar than /g/: Consonant coarticulation as a cause of diphthongization. In C. B. Chang \& H. J. Haynie (Eds.), Proceedings of the 26th West Coast Conference on Formal Linguistics 60-68. Somerville, MA: Cascadilla Proceedings Project.

Bar-El, Leora, Rosulek, Laura F., \& Sprowls, Lisa. (2017). Montana English and its place in the West. Speech in the Western States, Volume 2: The Mountain West. Publication of the American Dialect Society 102(1):107-38.

Bates, Douglas, Mächler, Martin, Bolker, Ben, \& Walker, Steve. (2015). Fitting linear mixed-effects models using lme4. Journal of Statistical Software 67(1):1-48.

Bauer, Matt, \& Parker, Frank. (2008). /æ/-raising in Wisconsin English. American Speech 83 (4):403-31.

Becker, Kara, Aden, Anna, Best, Katelyn, \& Jacobson, Haley. (2016). Variation in West Coast English: The case of Oregon. Speech in the Western States, Volume 1: The Coastal States. Publication of the American Dialect Society 101(1):107-34.

Benson, Erica J., Fox, Michael J., \& Balkman, Jared. (2011). The bag that Scott bought: The low vowels in northwest Wisconsin. American Speech 86(3):271-311.

Boberg, Charles. (2008). Regional phonetic differentiation in Standard Canadian English. Journal of English Linguistics 36(2):129-54.

Boersma, Paul, \& Weenink, David. (2013). Praat, a system for doing phonetics by computer (Version 5.3.53). http://www.praat.org.

Cardoso, Amanda, Hall-Lew, Lauren, Kementchedjhieva, Yova, \& Purse, Ruaridh. (2016). Between California and the Pacific Northwest: The front lax vowels in San Francisco English. Speech in the Western States, Volume 1: The Coastal States. Publication of the American Dialect Society 101 (1):33-54.

Chambers, J. K. (2000). World Enough and Time: Global Enclaves of the Near Future. American Speech 75:285-7.

Crosby, Drew, \& Dalola, Amanda. (2020). Begging for bags: BAG-raising and prescriptive ideologies in Spokane Washington. Proceedings of the Linguistic Society of America 5(1):354-68.

D'Onofrio, Annette, Eckert, Penelope, Podesva, Robert J., Pratt, Teresa, \& Van Hofwegen, Janneke. (2016). The low vowels in California's Central Valley. Speech in the Western States, Volume 1: The Coastal States. Publication of the American Dialect Society 101(1):11-32.

Evans, Betsy E. (2013). Seattle to Spokane: Mapping perceptions of English in Washington State. Journal of English Linguistics 41(3):268-91.

Freeman, Valerie. (2010). Using acoustic measures of hyperarticulation to quantify novelty and evaluation in a corpus of political talk shows. Master's thesis, University of Washington. https:// linguistics.washington.edu/research/graduate/using-acoustic-measures-hyperarticulation-quantifynovelty-and-evaluation-corpus.

. (2014). Bag, beg, bagel: Prevelar raising and merger in Pacific Northwest English. University of Washington Working Papers in Linguistics 32:1-23. http://depts.washington.edu/uwwpl/.

(2016). Style-shifting of prevelar merger more sensitive to setting than task. Presented at Experimental Approaches to Perception and Production of Language Variation, Vienna, Austria. https://www.academia.edu/29178183/Style-shifting_of_prevelar_merger_more_sensitive_to_setting_ than_task.

(2019). Prevelar merger in production vs. perception. In Proceedings of the International Congress on Phonetic Sciences, Sydney, Australia.

Fridland, Valerie, \& Kendall, Tyler. (2017). Speech in the Silver State. Speech in the Western States, Volume 2: The Mountain West. Publication of the American Dialect Society 102(1):139-64.

Fruehwald, Josef. (2010). SS ANOVA [Tutorial]. https://www.ling.upenn.edu/ joseff/ papers/fruehwald_ssanova.pdf.

Gu, Chong. (2014). Smoothing spline ANOVA models: R package gss. Journal of Statistical Software 58(5): 1-25. http://www.jstatsoft.org/v58/i05/.

Gunter, Kaylynn, Clayton, Ian, \& Fridland, Valerie. (2017). Pre-velar raising and categorization in Nevada English. Presented at the NorthWest Phonetics and Phonology Conference, Vancouver, BC.

Hall-Lew, Lauren. (2009). Ethnicity and phonetic variation in a San Francisco neighborhood. Doctoral dissertation, Stanford University.

(2010). Improved representation of variance in measures of vowel merger. In Proceedings of Meetings on Acoustics 9:1-10. 
Hay, Jennifer, Warren, Paul, \& Drager, Katie. (2006). Factors influencing speech perception in the context of a merger-in-progress. Journal of Phonetics 34: 458-84.

Ingle, Jennifer K., Wright, Richard A., \& Wassink, Alicia B. (2005). Pacific Northwest vowels: A Seattle neighborhood dialect study. Presented to the Acoustical Society of America, Vancouver, BC. https:// www.researchgate.net/publication/247093915_Pacific_northwest_vowels_A_Seattle_neighborhood_ dialect_study.

Jones, Jacqueline. (2015). I bag your pardon: The Albertan a / $\varepsilon$ vowel shift as a window into community grammars. Master's thesis, University of Calgary.

Kelley, Matthew C., \& Tucker, Benjamin V. (2020). A comparison of four vowel overlap measures. Journal of the Acoustical Society of America 147(1):137-45.

Labov, William (1994). Principles of linguistic change: Internal factors. Oxford: Blackwell.

Labov, William, Ash, Sharon, \& Boberg, Charles. (2006). Atlas of North American English: Phonetics, Phonology, and Sound Change. Berlin: Mouton de Gruyter.

McCloy, Daniel R. (2016). phonR: tools for phoneticians and phonologists. R package version 1.0-7.

McLarty, Jason, Kendall, Tyler, \& Farrington, Charlie. (2016). Investigating the development of the contemporary Oregonian English vowel system. Speech in the Western States, Volume 1: The Coastal States. Publication of the American Dialect Society 101(1):135-57.

Mellesmoen, Gloria. (2018). A remedial path to merger: Merger by phonological transfer in British Columbia English. Toronto Working Papers in Linguistics 40(1).

Milroy, L. (2002). Introduction: Mobility, Contact, and Language Change-Working with Contemporary Speech Communities. Journal of Sociolinguistics 6(1):3-15.

Nycz, Jennifer, \& De Decker, Paul. (2006). A new way of analyzing vowels: Comparing formant contours using Smoothing Spline ANOVA. Presented at New Ways of Analyzing Variation, Ohio State University, Columbus, OH. http://corpling.uis.georgetown.edu/shuoz/ssanova/ssanovapapers/NyczDeDecker_NWAV35_poster.pdf.

Nycz, Jennifer, \& Hall-Lew, Lauren. (2014). Best practices in measuring vowel merger. In Proceedings of Meetings on Acoustics 20:060008.

Ohala, John (2003). Phonetics and Historical Phonology. In B. Joseph and D. Janda (Eds.), The Handbook of Historical Linguistics. Malden, MA: Blackwell, 669-86.

Purnell, Thomas C. (2008). Prevelar raising and phonetic conditioning: The role of labial and anterior tongue gestures. American Speech 83(4):373-402.

R Core Team. (2020). R: A language and environment for statistical computing (Version 4.0.1). http:// www.R-project.org.

Reed, Carroll. (1952). The pronunciation of English in the state of Washington. American Speech 27 (3):186-9.

. (1961). The pronunciation of English in the Pacific Northwest. Language 37(4):559-64.

Riebold, John M. (2015). The social distribution of a regional change: / $\mathrm{cg}$, $\mathrm{gg}$, eg/ in Washington State. Doctoral dissertation, University of Washington.

Roeder, Rebecca, Onosson, Sky, \& D'Arcy, Alexandra. (2018). Joining the western region: Sociophonetic shift in Victoria. Journal of English Linguistics 46(2):87-112.

Rosen, Nicole, \& Skriver, Crystal. (2015). Vowel patterning of Mormons in southern Alberta, Canada. Language and Communication 42:104-15.

Squizzero, Robert (2009). Fronting of / a / and / $/$ / before /g/ in Seattle English: Effects of style and gender. Undergraduate honors thesis, University of Washington. https://linguistics.washington. edu/research/undergraduate/effects-style-and-gender-fronting-and-raising-ae-and-e-g-seattleenglish.

Stanley, Joseph A. (2018a). Changes in the timber industry as a catastrophic event: BAG-raising in Cowlitz County, Washington. Penn Working Papers in Linguistics 24(2). https://repository.upenn. edu/pwpl/vol24/iss $2 / 16 /$.

(2018b). The differences between and within BEG and BAG: Phonological, morphological, and lexical effects in prevelar raising. Presented at New Ways of Analyzing Variation, New York University, New York, NY. https://joeystanley.com/downloads/181019-nwav47.pdf.

(2019a). Are BEG and BAG-raising distinct? Regional patterns in prevelar raising in North American English. Presented to the American Dialect Society, New York, NY. https://joeystanley. com/downloads/190104-ads2019_prevelar.pdf.

(2019b). Phonological patterns in BEG-raising. UGA Working Papers in Linguistics 4, 69-91. https://ling.franklin.uga.edu/wp2019-Stanley.

Stanley, Joseph. (2019c, February 7). A tutorial in measuring vowel overlap in R [blog post]. https:// joeystanley.com/blog/a-tutorial-in-calculating-vowel-overlap. 
Sullivan, Lisa. (2020). The production-perception link in phonologically-conditioned pre-velar /æa/raising. $\mathrm{PhD}$ candidacy qualifying paper, University of Toronto. http://lisasullivan.ca/wpcontent/uploads/2020/04/1sullivan_gp1.pdf.

Swan, Julia T. (2016). Canadian English in the Pacific Northwest: A phonetic comparison of Vancouver, $\mathrm{BC}$ and Seattle, WA. In Proceedings of the 2016 Annual Conference of the Canadian Linguistic Association, Calgary, AB.

(2020). Bag across the border: Sociocultural background, ideological stance, and bag raising in Seattle and Vancouver. American Speech 95(1):46-81.

Thomas, Erik R., \& Kendall, Tyler. (2010). NORM: The vowel normalization and plotting suite (Version 1.1). http://lingtools.uoregon.edu/norm/norm1.php.

Wassink, Alicia B. (2015). Sociolinguistic patterns in Seattle English. Language Variation and Change 27:31-58.

Wassink, Alicia B. (2016). The vowels of Washington State. Speech in the Western States, Volume 1: The Coastal States. Publication of the American Dialect Society 101(1):77-105.

Wassink, Alicia B., \& Riebold, John M. (2013). Individual variation and linguistic innovation in the American Pacific Northwest. Presented at the Workshop on Sound Change Actuation, Chicago Linguistic Society, Chicago, IL. https://www.semanticscholar.org/paper/Individual-Variationand-Linguistic-Innovation-in-Wassink-Riebold/25de9506ad84a21b607bd9e1e612d5eb7042908c.

Wedel, Andrew, Kaplan. Abby, \& Jackson, Scott. (2013). High functional load inhibits phonological contrast loss: A corpus study. Cognition 128(2):179-86.

Yuan, Jiahong, \& Liberman, Mark. (2008). Speaker identification on the SCOTUS corpus. Proceedings of Acoustics '08 Paris, 5687-5690. Computer software (Version 1.003), http://www.ling.upenn. edu/phonetics/P2FA/.

Zeller, Christine. (1997). The investigation of a sound change in progress: /æ/ to /e/ in Midwestern American English. Journal of English Linguistics 25(2):142-55. 
A P PENDIX

TABLE A. Results of linear mixed-effects models for each Nearey-normalized formant (F1 or F2) at midpoint with Vowel as a fixed effect and individual Speaker and Word as random effects

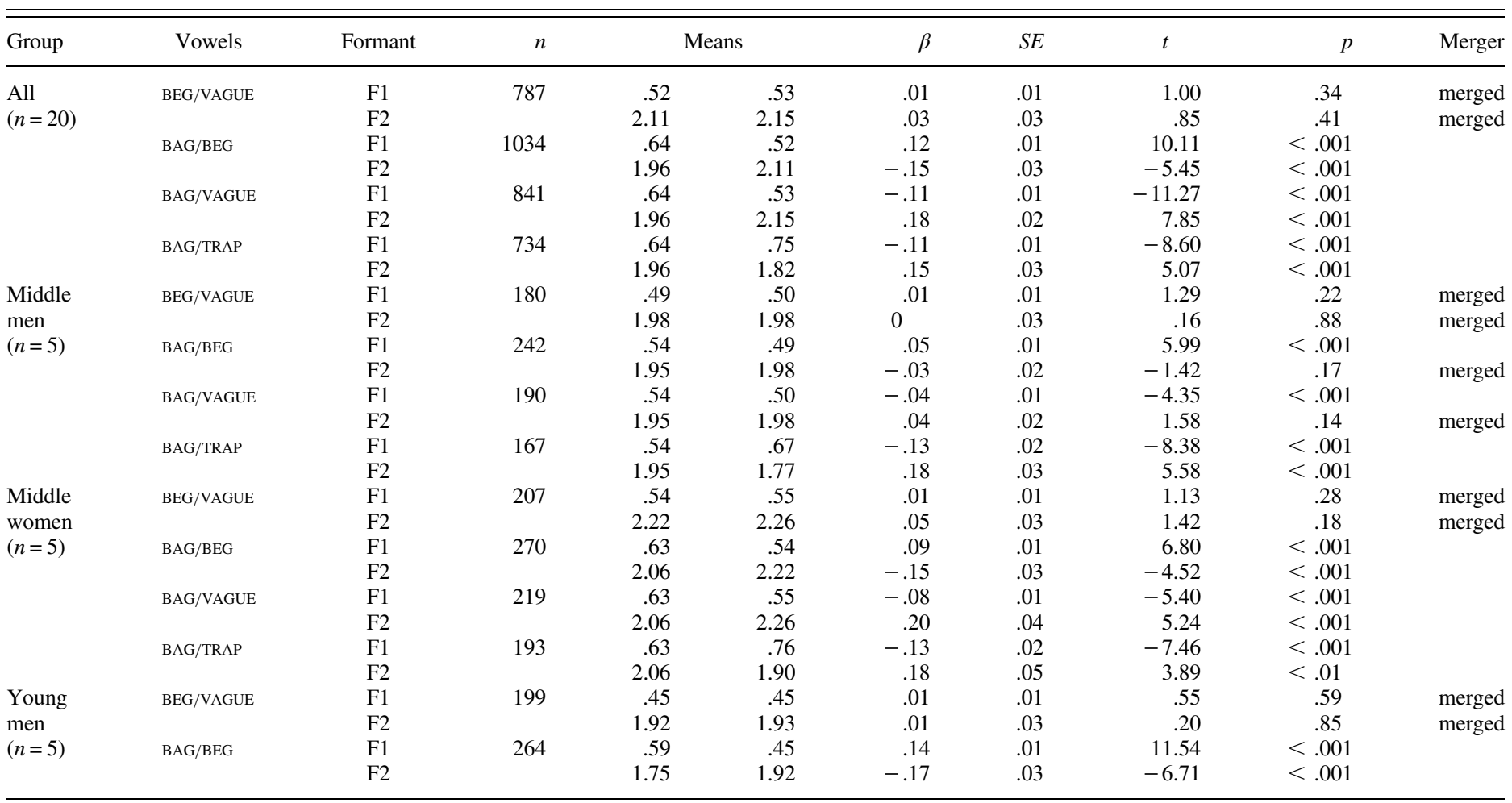


TABle A. Continued

\begin{tabular}{|c|c|c|c|c|c|c|c|c|c|c|}
\hline Group & Vowels & Formant & $n$ & & & $\beta$ & $S E$ & $t$ & $p$ & Merger \\
\hline \multirow{12}{*}{$\begin{array}{l}\text { Young } \\
\text { women } \\
(n=5)\end{array}$} & BAG/VAGUE & $\mathrm{F} 1$ & 215 & .59 & .45 & -.14 & .01 & -11.52 & $<.001$ & \multirow{12}{*}{$\begin{array}{l}\text { merged } \\
\text { merged }\end{array}$} \\
\hline & & $\mathrm{F} 2$ & & 1.75 & 1.93 & .18 & .02 & 7.99 & $<.001$ & \\
\hline & BAG/TRAP & $\mathrm{F} 1$ & 190 & .59 & .68 & -.09 & .02 & -5.70 & $<.001$ & \\
\hline & & $\mathrm{F} 2$ & & 1.75 & 1.68 & .07 & .03 & 2.65 & $<.05$ & \\
\hline & BEG/VAGUE & $\mathrm{F} 1$ & 201 & .61 & .61 & .02 & .03 & .63 & .54 & \\
\hline & & $\mathrm{F} 2$ & & 2.32 & 2.38 & .04 & .04 & 1.03 & .33 & \\
\hline & $\mathrm{BAG} / \mathrm{BEG}$ & $\mathrm{F} 1$ & 258 & .80 & .61 & .19 & .02 & 8.84 & $<.001$ & \\
\hline & & $\mathrm{F} 2$ & & 2.09 & 2.32 & -.23 & .03 & -7.16 & $<.001$ & \\
\hline & BAG/VAGUE & $\mathrm{F} 1$ & 217 & .80 & .61 & -.19 & .02 & -11.54 & $<.001$ & \\
\hline & & $\mathrm{F} 2$ & & 2.09 & 2.38 & .28 & .02 & 15.12 & $<.001$ & \\
\hline & BAG/TRAP & $\mathrm{F} 1$ & 184 & .80 & .89 & -.09 & .02 & -5.47 & $<.001$ & \\
\hline & & $\mathrm{F} 2$ & & 2.09 & 1.94 & .15 & .02 & 8.69 & $<.001$ & \\
\hline
\end{tabular}

